\title{
Neuropsychological profiles of adult bipolar disorder patients with and without comorbid attention-deficit hyperactivity disorder
}

\author{
Sara Salarvan ${ }^{1}$, Timea Sparding ${ }^{1}$, Caitlin Clements ${ }^{2,3,4}$, Eleonore Rydén ${ }^{5}$ and Mikael Landén ${ }^{1,3^{*}}$ (i)
}

\begin{abstract}
Background: Comorbid attention-deficit/hyperactivity disorder (ADHD) is common in bipolar disorder and associated with worse outcomes. Cognitive testing might be a tool to identify this group. Here we compare the neuropsychological profiles of bipolar disorder patients with (BD + CADHD) and without (BD - cADHD) childhood attentiondeficit hyperactivity disorder.

Methods: Adult patients with BD - cADHD ( $n=66), B D+c A D H D(n=32)$, and healthy controls $(n=112)$ were tested using a comprehensive battery of neuropsychological tests. Patients underwent rigorous diagnostic assessments for bipolar disorder and ADHD, as well as a parental interview to establish childhood ADHD.

Results: The neuropsychological profiles of the groups were similar, except that the BD + cADHD group performed significantly worse on working memory. Working memory did not differ between those in the BD + cADHD group who only had a history of childhood ADHD and those that still met criteria for ADHD in adulthood.

Conclusions: Cognitive testing had limited power to differentiate between bipolar disorder adults with and without childhood ADHD. The BD + CADHD subgroup cannot explain the significant cognitive heterogeneity seen in bipolar disorder patients.
\end{abstract}

Keywords: Attention-deficit/hyperactivity disorder, Bipolar disorder, Comorbidity, Cognitive function, Neuropsychology

\section{Introduction}

The prevalence of comorbid attention-deficit/hyperactivity disorder (ADHD) in adults with bipolar disorder (BD) ranges between 9.5 and $28 \%$ (Nierenberg et al. 2005; Rydén et al. 2009; Torres et al. 2015). Although the longitudinal course of illness differs between BD and ADHD, where $\mathrm{BD}$ is an episodic disorder and ADHD is a persistent condition, differentiating between ADHD and BD is sometimes a challenge (Brus et al. 2014). BD and ADHD feature partially overlapping symptoms that cross-sectionally might be interpreted as hypomanic symptoms,

\footnotetext{
*Correspondence: mikael.landen@gu.se

1 Department of Psychiatry and Neurochemistry, Institute

of Neuroscience and Physiology, The Sahlgrenska Academy, University

of Gothenburg, Sahlgrenska University Hospital, Blå Stråket 15, 413

45 Gothenburg, Sweden

Full list of author information is available at the end of the article
}

such as talkativeness, restlessness, impulsivity, distractibility, and affective lability.

The overlap of symptoms not only begets diagnostic challenges, it also raises the question if so-called 'comorbid' BD and ADHD condition might be an artefact produced by the diagnostic system (Wingo and Ghaemi 2007). The comorbidity concept is, however, supported by the fact that a majority of patients with comorbid $\mathrm{BD}$ and ADHD maintain both diagnoses after correction for overlapping symptoms (Milberger et al. 1995). Moreover, BD with comorbid ADHD presents a worse course of illness than BD without ADHD, including earlier onset of bipolar disorder (Nierenberg et al. 2005; Tamam et al. 2008; Rydén et al. 2009; Karaahmet et al. 2013; Perroud et al. 2014), as well as higher frequency of mood episodes (Nierenberg et al. 2005; Tamam et al. 2008; Rydén et al. 2009; Perroud et al. 2014; Torres et al. 2015), suicide 
attempts (Nierenberg et al. 2005; Torres et al. 2015; Harmanci et al. 2016), and interpersonal violence (Nierenberg et al. 2005; Rydén et al. 2009). This means that it is clinically important to identify BD patients with comorbid ADHD. It is noteworthy that the mere history of childhood ADHD, irrespective of adult ADHD status, is sufficient to generate a worse course of illness in BD (Rydén et al. 2009; Torres et al. 2015). This suggests that reviewing childhood history is important when assessing BD prognosis.

BD has been associated with general cognitive impairment across different cognitive domains (Mann-Wrobel et al. 2011; Sparding et al. 2015). Meta-analyses suggest that executive function, verbal memory, and attention/ working memory are particularly affected (Robinson and Ferrier 2006; Torres et al. 2007; Arts et al. 2008; Bourne et al. 2013). However, more recent studies suggest that cognitive impairment may not be a general trait in $\mathrm{BD}$, but limited to specific subgroups (Burdick et al. 2014; Bora et al. 2016; Sparding et al. 2017): one group of patients that perform within the normal range, and one or more subgroups that exhibit varying degrees of cognitive impairment. It remains unknown what accounts for this cognitive heterogeneity in $\mathrm{BD}$, but a possible explanation is that the cognitively impaired group suffer from comorbid conditions, e.g., ADHD. Cognition in adults with ADHD shows general impairments across multiple cognitive domains, with possible emphasis on impaired attention, inhibition, and verbal memory (Hervey et al. 2004; Schoechlin and Engel 2005). Despite this, studies of cognitive function in BD have generally not accounted for potential comorbid ADHD.

Examining cognition in $\mathrm{BD}$ patients with and without comorbid ADHD might also serve to identify a BD subgroup with poor outcome in need for specific interventions. One study compared adults with $B D, A D H D$, $\mathrm{BD}+\mathrm{ADHD}$, and healthy controls across a broad spectrum of cognitive domains, but found no significant differences between $\mathrm{BD}$ and $\mathrm{BD}+\mathrm{ADHD}$ (Torres et al. 2017). However, the assessment of comorbid ADHD did not include any informant report. The accuracy of retrospective self-reports of childhood symptoms has been questioned (Barkley et al. 2002; Mannuzza et al. 2002), and it is considered best practice to include multiple sources of information, e.g., a parental or next of kin interview (Davidson 2008). Furthermore, replication is needed given the limited sample size in the previous study (Torres et al. 2017).

The aim of the present study was to compare the neuropsychological profiles of adult $\mathrm{BD}$ patients with childhood ADHD (BD+cADHD) and without childhood ADHD (BD - cADHD) in a cohort with meticulous assessment of childhood as well as adult ADHD.

\section{Materials and methods}

The participants in this study were recruited from a bipolar outpatient clinic at the Northern Stockholm psychiatric clinic in Sweden between October 2005 and April 2008, as a part of the St. Göran Bipolar project. The project and the clinical assessment process has been described in detail elsewhere (Rydén et al. 2009). In brief, the project is a prospective, longitudinal study providing assessment, treatment, and follow-up of patients with $\mathrm{BD}$. For the present study, we included patients who were at least 18 years of age, met the DSM-IV criteria for BD type I or II, and consented orally and in writing to participate in the project. Exclusion criteria were a history of intellectual disability (IQ $<70)$, organic brain disorder, neurological disorder, and severe medical conditions. The study was approved by the ethical review board in Stockholm, Sweden.

\section{Assessment of bipolar disorder}

The baseline clinical assessment was made by a psychiatrist or a resident in psychiatry using the affective disorder evaluation (ADE), a diagnostic instrument originally developed and used in the systematic treatment enhancement program of bipolar disorder (STEP-BD) (Sachs et al. 2003) that had been slightly modified to suit Swedish conditions. The ADE includes the affective module of the Structural Clinical Interview for DSM-IV (SCID). The Mini International Neuropsychiatry Interview (M.I.N.I) (Sheehan et al. 1998) was used to screen for other psychiatric diagnoses. Other information gathered with the ADE include a social anamnesis, number of lifetime affective episodes and their characteristics, alcohol and drug abuse, somatic illnesses, histories (childhood, family, and treatment), and suicide attempts.

Patients completed two self-report questionnaires to screen for alcohol and substance abuse: the Alcohol Use Disorders Identification Test (AUDIT) (Saunders et al. 1993) and the Drug Use Disorders Identification Test (DUDIT) (Berman et al. 2005). Taking information from all available sources into account, the final diagnostic decision was made at a diagnostic case conference by a consensus panel of experienced board-certified psychiatrists specialized in bipolar disorder.

\section{Assessment of ADHD}

The assessment of childhood and current ADHD symptoms was completed after the bipolar diagnosis had been established and at a time when the patient was considered stable with respect to mood symptoms (but not always completely asymptomatic) by the treating physician. The ADHD clinical assessments required approximately $1.5 \mathrm{~h}$ and were conducted by a second independent boardcertified psychiatrist (E.R.). To assess current ADHD 
symptoms, the Adult ADHD Self-Report Scale (ASRS) (Kessler et al. 2005) and the BROWN ADD assessment scale (Brown 2008) were used. To retrospectively assess childhood symptoms of ADHD, the Wender Utah Rating Scale (WURS-25) (Ward et al. 1993) was used. To obtain objective information about childhood symptoms, the Autism-Tics, ADHD, and other comorbidities (A-TAC) interview was completed with a parent or other next of kin in a telephone interview when possible. The A-TAC is a broad screening instrument to assess child psychiatric disorders with a particular strength in assessing ADHD and autism spectrum disorders symptoms (Mårland et al. 2017). The A-TAC interview took approximately $30 \mathrm{~min}$ to complete.

\section{Pure bipolar group, and bipolar disorder + childhood ADHD group}

The present study compared the neuropsychological profiles of two groups:

1. The bipolar disorder and childhood ADHD group $(B D+c A D H D)(\mathrm{n}=32)$ fulfilling

a. criteria for bipolar disorder type I or II, and

i. criteria for childhood ADHD alone (defined as an A-TAC ADHD score $\geq 8$, and/or a WURS-25 score $\geq 46)(\mathrm{n}=14)$, or

ii. criteria for childhood and current ADHD (defined as meeting childhood ADHD criteria above, and currently meeting DSMIV criteria for any of the three subtypes of ADHD) $(\mathrm{n}=18)$

2. The bipolar disorder without childhood ADHD group $(B D-c A D H D)(\mathrm{n}=66)$ fulfilling criteria for bipolar disorder type I or II without a history of childhood ADHD.

\section{Healthy control group}

In supplementary analyses, we also included a healthy control group randomly selected by Statistics Sweden. Details of the recruitment, in- and exclusion criteria can be found elsewhere (Rolstad et al. 2015; Abe et al. 2018). Briefly, eligible controls were scheduled for a personal examination by a psychiatrist using M.I.N.I. and selected parts of the ADE. Exclusion criteria for controls were any current psychiatric disorder, a family history of schizophrenia or bipolar disorder in first-degree relatives, drug or alcohol abuse, and neurological conditions.

\section{Neuropsychological test procedure}

The baseline assessments of the St. Göran Bipolar project consisted of a neuropsychological test battery administered by a trained psychologist according to standard instructions. The testing usually required 2 sessions to complete. Patients were tested in a stable mood (but not always completely asymptomatic) as judged by the treating physician. Present mood status was assessed by administrating the Montgomery-Åsberg Depression Rating Scale (MADRS) (Åsberg and Schalling 1979) and the Young Mania Rating Scale (YMRS) (Young et al. 1978). Patients with $>14$ on either scale were not considered to be in clinically stable mood and excluded from this study.

The neuropsychological assessment included a broad set of cognitive tests routinely employed in clinical settings (Lezak 2012): Wechsler Adult Intelligence Scale, third edition (WAIS-III) measuring intellectual ability; Rey Complex Figure test (RCFT) primarily measuring visuospatial memory; Claeson Dahl Verbal Learning and Retention test measuring verbal memory; Conners' Continuous Performance Test 2 (CPT 2) measuring different aspects of attention; and five tests from the Delis-Kaplan Executive Function System (D-KEFS) measuring different aspects of executive functions (Trail Making Test, Design fluency test, Verbal Fluency Test, Color-Word Interference Test, Tower Test).

For the current study, we selected 10 subtests that cover a broad range of cognitive domains and identify the largest systematic variation in this cohort of patients with bipolar disorder (Sparding et al. 2015, 2017). These tests were: Verbal Comprehension, Perceptual Organization, Working Memory and Processing speed indexes from WAIS-III; Commission- and Omission errors from CPT 2 (measuring concentration/focused attention); Color Word 4 from D-KEFS (measuring cognitive flexibility); and Total achievement Score on Tower Test (measuring planning and decision making).

\section{Statistical analyses}

All data were analysed with SPSS version 23 . The groups were compared with t-tests for continuous variables, and chi-square tests for categorical variables. Equal variances between groups was tested with Levene's test and corrected if $\mathrm{p}<0.05$. Effect sizes were calculated with Cohen's $d$ value (where 0.2 corresponds to small, 0.5 to moderate, and 0.8 to large effect size). We also conducted complementary analyses comprising a healthy control group (Additional file 1: Tables S1a and S2). We compared the three groups using one-way analysis of variance (ANOVA). Specific group differences were examined with post-hoc Bonferroni tests. Statistical significance was set at a two-sided $\mathrm{p}$-value of $<0.05$. 


\section{Results}

The clinical characteristics of the BD - cADHD and the $\mathrm{BD}+\mathrm{cADHD}$ groups are shown in Table 1 . The groups did not differ with respect to sex, age, type of bipolar disorder, or global IQ (as measured by WAIS-III). The prevalence of comorbid psychiatric diagnoses other than ADHD was numerically (but not statically significant, $\mathrm{p}=0.09$ ) higher in the $\mathrm{BD}+\mathrm{cADHD}$ group compared with the BD - cADHD group. Specific comorbidities in each group are outlined in Additional file 1: Table S1b. The BD+cADHD group was significantly younger at age of first psychiatric symptom, as well as at age of first affective episode. The number of mixed episodes was significantly higher for the BD + cADHD group, whereas no group differences were found regarding number of manic, hypomanic, or depressive episodes. Lithium treatment was significantly more common in the BD-cADHD group, while other mood stabilizers were more common in the BD + cADHD group. No differences were found regarding level of education, employment status, or number of sick-leave days the previous year.

\section{Neuropsychological profiles}

The results of the neuropsychological test scores are shown in Table 2. The BD-cADHD group performed significantly better than the BD + cADHD group on WAIS Working Memory Index ( $(89)=2.15, \mathrm{p}=0.03$ ) with a moderate effect size $(\mathrm{d}=0.52)$. For all other measures, the group differences were much smaller $(\mathrm{d}=-0.02$ to 0.29 ) and no other group differences were statistically significant.

In a posthoc analysis, we split the $\mathrm{BD}+\mathrm{cADHD}$ group into individuals fulfilling only childhood ADHD criteria $(\mathrm{n}=11)$ and individuals fulfilling both childhood and current ADHD criteria $(\mathrm{n}=17)$. We compared the

Table 1 Clinical characteristics of the bipolar disorder group without childhood ADHD (BD - CADHD) and the bipolar disorder group with childhood ADHD (BD+ CADHD)

\begin{tabular}{|c|c|c|c|}
\hline & $\mathrm{BD}-\mathrm{cADHD}\left(n=58-66^{\mathrm{a}}\right)$ & $\mathrm{BD}+\mathrm{cADHD}\left(n=24-32^{\mathrm{a}}\right)$ & $p$-value \\
\hline Male, N (\%) & $28(42.4)$ & $15(46.9)$ & .68 \\
\hline Female, N (\%) & $38(57.6)$ & $17(53.1)$ & \\
\hline Age, mean (SD) & $37.7(13.6)$ & $35.2(11.5)$ & .36 \\
\hline Age at first psychiatric symptom, mean (SD) & $20.4(8.4)$ & $14.8(10)$ & .01 \\
\hline Age at first affective episode, mean (SD) & $20.9(8.1)$ & $16.0(7.1)$ & .01 \\
\hline Bipolar I, N (\%) & $44(67.7)$ & $15(55.6)$ & .27 \\
\hline Bipolar II, N (\%) & $21(32.3)$ & $12(44.4)$ & \\
\hline Any comorbid psychiatric diagnosis, N (\%) & $36(58.1)$ & $20(76.9)$ & .09 \\
\hline AUDIT, mean (SD) & $5.5(4.5)$ & $6.6(7)$ & .49 \\
\hline DUDIT, mean (SD) & $0.9(2.5)$ & $2.6(6.6)$ & .22 \\
\hline MADRS, mean (SD) & $4.6(4)$ & $3.9(3.3)$ & .40 \\
\hline YMRS, mean (SD) & $1.3(2.1)$ & $2(2.7)$ & .16 \\
\hline \multicolumn{4}{|l|}{ No of mood episodes, mean (SD) } \\
\hline Mania & $1.9(2.7)$ & $1.7(2.9)$ & .81 \\
\hline Hypomania & $4.3(7.7)$ & $7.3(11.8)$ & .16 \\
\hline Mixed & $0.4(1.8)$ & $6(10.4)$ & .01 \\
\hline Depressive & $8.9(10.9)$ & $16(21.1)$ & .11 \\
\hline History of attempted suicide and/or self-harm, N (\%) & $22(34.4)$ & $13(48.1)$ & .22 \\
\hline \multicolumn{4}{|l|}{ Pharmacological treatment, N (\%) } \\
\hline Lithium & $46(70.8)$ & $11(36.7)$ & .00 \\
\hline Other mood stabilizers & $13(20)$ & $15(50)$ & .00 \\
\hline Antidepressant & $24(36.9)$ & $10(33.3)$ & .73 \\
\hline Antipsychotics & $13(20)$ & $5(16.7)$ & .70 \\
\hline Central stimulants & 0 & 0 & \\
\hline WAIS-III estimated IQ & $107.9(16)$ & $106.4(10.9)$ & .60 \\
\hline At least 2 years university education, $N(\%)$ & $38(58.5)$ & $15(55.6)$ & .80 \\
\hline Working, N (\%) & $47(73.4)$ & $18(66.7)$ & .51 \\
\hline Sick-leave days previous 12 months, mean (SD) & $116.7(145.6)$ & $91.3(134.8)$ & .45 \\
\hline
\end{tabular}

\footnotetext{
a Data were missing for some patients, therefore the $\mathrm{N}$ varies
} 
Table 2 Comparison of neuropsychological test performance of the bipolar disorder group without childhood ADHD (BD - CADHD) and the bipolar disorder group with childhood ADHD (BD + CADHD)

\begin{tabular}{|c|c|c|c|c|c|}
\hline & $\begin{array}{l}\text { BD - cADHD } \\
\left(n=56-64^{\mathrm{a}}\right)\end{array}$ & $\begin{array}{l}\text { BD + CADHD } \\
\left(n=23-31^{a}\right)\end{array}$ & $t$-value & $p$ value & Cohen's $d$ \\
\hline & Mean (SD) & Mean (SD) & & & \\
\hline WAIS-III: Verbal Comprehension Index & $109.8(12.9)$ & $112.5(10.6)$ & -.98 & .33 & -.23 \\
\hline WAIS-III: Perceptual Organization Index & $109.4(16.5)$ & $106.1(14.4)$ & .91 & .37 & .21 \\
\hline WAIS-III: Working Memory Index & $102.2(14.9)$ & $95.4(11)$ & 2.15 & .03 & .52 \\
\hline WAIS-III: Processing Speed Index & $99.1(15.8)$ & $95.9(10.9)$ & 1.12 & .27 & .24 \\
\hline CPT2 omission errors ${ }^{b}$ & $53.5(15.8)$ & $53.9(16.7)$ & -.10 & .92 & -.02 \\
\hline CPT2 comission errors ${ }^{b}$ & $54.2(9.9)$ & $54.4(10.1)$ & -.05 & .96 & -.02 \\
\hline ColorWord 4 (Inh/Swi) & $9.9(3)$ & $9.5(3.1)$ & .66 & .51 & .13 \\
\hline Tower test total & $11.4(3.3)$ & $10.4(3.7)$ & 1.17 & .25 & .29 \\
\hline RCFT: immediate recall & $43.5(14.2)$ & $41.6(16)$ & .70 & .49 & .15 \\
\hline Claeson Dahl verbal learning & $46(12.9)$ & $48.8(9.3)$ & -1.15 & .25 & -.25 \\
\hline
\end{tabular}

a Data were missing for some patients, therefore the $\mathrm{N}$ varies

b Higher score indicates better performance on all tests except CPT, where lower score indicates better performance

WAIS Working Memory Index but found no difference [mean (SD) 94.6 (11.9), and 95.9 (10.8), respectively, $t$ $(26)=-0.32, \mathrm{p}=0.75]$. The $\mathrm{N}$ differs from the main analysis because some individuals did not have complete data on the WAIS working memory variable.

In supplementary analyses, we compared the patient groups with a healthy control group to show the severity of cognitive impairment (Additional file 1: Table S2). Results show that both patient groups performed worse than controls on several tests. There was a significant difference across all three groups with respect to Working memory, but the difference between the two bipolar subgroups was not significant in the post-hoc Bonferroni test. Note that comparisons of cognitive function between cases and controls in this cohort have been published previously (Pålsson et al. 2013; Sparding et al. 2015).

\section{Discussion}

This study compared the neuropsychological profiles of adult BD patients with and without comorbid childhood ADHD. We payed particular attention to childhood history and performed interviews with parents or next of kin to establish childhood ADHD diagnoses. The main finding was that the neuropsychological profiles of the groups were similar. The only exception was that the $\mathrm{BD}+\mathrm{cADHD}$ group performed significantly worse on WAIS working memory than the BD-cADHD group, but that finding would not withstand correction for multiple testing $(\mathrm{N}=10)$.

There are few previous studies in this area. Our finding of small overall cognitive differences between BDcADHD and BD + cADHD is largely in agreement with the results of Torres and colleagues (Torres et al. 2017) who found no significant differences between $\mathrm{BD}$ and BD + ADHD. Another study (Silva et al. 2014) used only the Wisconsin Card Sorting Test and found that $\mathrm{BD}+\mathrm{ADHD}$ showed set-shifting difficulties compared with ADHD and healthy controls. One study comparing adolescents with BD, ADHD, BD + ADHD, and healthy controls (Rucklidge 2006) found that the BD group in general performed similar to controls, whereas $\mathrm{BD}$ with comorbid ADHD was associated with cognitive impairment. The greatest deficits in the BD+ADHD group were found in verbal memory and inhibitory control. Working memory was impaired only in the ADHD group.

It is noteworthy that the few studies comparing $\mathrm{BD}$ and ADHD with respect to cognition suggest that differences were directly or indirectly attributable to working memory impairment in ADHD (Torralva et al. 2011; Baez et al. 2014). With the caveat that our results were not corrected for multiple comparisons, the finding of worse working memory of moderate effect size in the $\mathrm{BD}+\mathrm{cADHD}$ group is interesting because conceptual models of ADHD place deficits in working memory as either a core feature of the disorder (Rapport et al. 2001), or as an area of secondary but fundamental impairment (Barkley 1997). In fact, a meta-analysis examining working memory in adults with ADHD found deficits of moderate effect size and concluded that working memory impairment in ADHD persist into adulthood (Matt Alderson et al. 2013).

Drilling deeper into the BD+cADHD group, we found no difference in working memory between those who met criteria for ADHD in childhood as well as adulthood, and those who only did so in childhood. 
This indicates that adults with BD with a history of childhood ADHD are likely to show working memory impairments regardless of current ADHD status.

Our findings have three important clinical implications. First, previous studies have found that BD with comorbid ADHD is associated with worse course of illness, calling for instruments to readily identify this group clinically (Rydén et al. 2009; Torres et al. 2015). Unfortunately, this study suggests that cognitive testing is not likely to be a valuable tool to differentiate between $\mathrm{BD}$ with and without ADHD given that we found quite similar neuropsychological profiles. This might be surprising since cognitive testing is considered to be an essential source of information in ADHD assessment. But there is in fact no agreed upon cognitive profile specific for ADHD (Davidson 2008), nor is there consensus on a testing battery that would identify cognitive impairments in BD [although there have been suggestions (Yatham et al. 2010; Sparding et al. 2015)]. This absence of disorder-specific cognitive profiles might be due to inherent limitations with current neuropsychological batteries or that cognitive impairments are orthogonal to psychiatric syndrome diagnoses.

Second, our results show that childhood ADHD was associated with impaired working memory in $\mathrm{BD}$ regardless of whether the diagnosis persisted into adulthood or not. This aligns with studies indicating that the mere history of childhood ADHD is sufficient to generate a worse course of bipolar illness (Rydén et al. 2009; Torres et al. 2015). Other studies have found cognitive impairment in BD to be associated with worse course of illness (Robinson and Ferrier 2006; Bourne et al. 2013)-with the highest correlation for working memory-and poorer everyday functioning (Depp et al. 2012). Hence, future research could investigate in more detail if cognitive testing focusing on working memory together with a thorough assessment of childhood symptoms of ADHD might be of value in identifying a group of BD patients at risk for poor outcomes.

Third, cognitive impairments observed in BD patients as a group have been attributed to one or more subgroups with more pronounced impairment (Burdick et al. 2014; Bora et al. 2016; Sparding et al. 2017). So far, no proposed characteristics of these cognitive subgroups have been able to explain the cognitive variability, i.e., bipolar subtype (Pålsson et al. 2013; Bora 2018), prior psychotic manifestations (Savitz et al. 2009; Bora 2018), number of affective episodes (Mann-Wrobel et al. 2011), residual mood symptoms, or medication (Bourne et al. 2013). Our findings suggest that nor is comorbid ADHD likely to explain the heterogeneous cognitive performance in $\mathrm{BD}$ beyond working memory deficits.
Some limitations of this study should be considered. First, although the sample size was on par with previous studies in the area, a limited number of study subjects might have affected the possibility to detect group differences with ensuing risk of type II errors. Second, we did not correct for multiple comparisons; doing so would revoke the group difference in working memory. Moreover, in the supplementary analyses where a healthy control group was added, working memory was no longer statistically significantly between the bipolar disorder groups. Third, ADHD is a childhood onset diagnosis that in this study was made in retrospect. Even though we used validated instruments to assess childhood symptoms, conducted a separate diagnostic interview focusing on ADHD, and even included an interview with nextof-kin when possible, this study design is susceptible to recall bias. Fourth, although not statistically significant, there were more $\mathrm{BD}$ II patients in the $\mathrm{BD}+\mathrm{cADHD}$ group. We did not find any differences between BD I and BD II in a previous study (Sparding et al. 2015,), but a recent meta-analyses found that BD I performed significantly worse than BD II with respect to global cognition, verbal memory, processing speed, and executive functioning speed and accuracy (Bora 2018). Fifth, the use of mood stabilizers differed such that lithium was more common in the BD - cADHD group whereas other mood stabilizers (e.g., valproate, lamotrigine) were more common in the BD + cADHD group. It cannot be excluded that medication might affect cognitive performance.

\section{Conclusions}

Cognitive performance was similar in bipolar disorder patients with and without ADHD in childhood, except that the former group performed worse on working memory. This means that comorbid ADHD cannot explain the cognitive heterogeneity seen in bipolar disorder patients, and that cognitive testing is not likely to be useful for differentiating between BD with and without ADHD.

\section{Additional file}

Additional file 1. Additional tables.

\section{Acknowledgements}

We wish to thank the participants in this study. We thank Björn Hultman and Pascal Borgström for help with the neuropsychological test battery. We also wish to thank staff at the St. Göran bipolar affective disorder unit, including study nurse Lena Lundberg and data manager Mathias Kardell.

\section{Authors' contributions}

TS and ML conceived and designed the study. SS analyzed the data and wrote the first draft of the manuscript. SS, TS, CC, ER, and ML interpreted the data and contributed to the writing of the final manuscript. All authors agreed with 
the results and conclusions of this article. All authors read and approved the final manuscript.

\section{Funding}

This research was supported by the Swedish Research Council (2018-02653), and the Swedish Federal Government under the LUA/ALF agreement (ALF 20170019 and ALFGBG-716801). SS was funded by Region Västra Götaland.

\section{Availability of data and materials}

The data that support the findings of this study are available on reasonable request from the corresponding author (ML). The data are not publicly available due to information that could compromise research participant privacy.

\section{Ethics approval and consent to participate}

The study was approved by the Ethics committee of the Karolinska Institutet, Stockholm, Sweden (2005/554-31/3). All study participants provided oral and written consent to participate after given full information about the study.

\section{Consent for publication}

Not applicable.

\section{Competing interests}

The authors declare that they have no competing interests.

\begin{abstract}
Author details
${ }^{1}$ Department of Psychiatry and Neurochemistry, Institute of Neuroscience and Physiology, The Sahlgrenska Academy, University of Gothenburg, Sahlgrenska University Hospital, Blå Stråket 15, 41345 Gothenburg, Sweden. ${ }^{2}$ Department of Psychology, University of Pennsylvania, 3720 Walnut Street, Philadelphia, PA 19104, USA. ${ }^{3}$ Department of Medical Epidemiology and Biostatistics, Karolinska Institutet, Stockholm, Sweden. ${ }^{4}$ Center for Autism Research, The Children'S Hospital of Philadelphia, 2716 South St, Philadelphia, PA 19104, USA. ${ }^{5}$ Department of Clinical Neuroscience, Karolinska Institutet, Stockholm, Sweden.
\end{abstract}

Received: 27 February 2019 Accepted: 14 June 2019

Published online: 28 June 2019

\section{References}

Abe C, Rolstad S, Petrovic P, Ekman CJ, Sparding T, Ingvar M, et al. Bipolar disorder type I and II show distinct relationships between cortical thickness and executive function. Acta Psychiatr Scand. 2018;138:325-35.

Arts B, Jabben N, Krabbendam L, Van Os J. Meta-analyses of cognitive functioning in euthymic bipolar patients and their first-degree relatives. Psychol Med. 2008;38:771-85.

Åsberg M, Schalling D. Construction of a new psychiatric rating instrument, the comprehensive psychopathological rating scale (CPRS). Prog NeuroPsychopharmacol. 1979;3:405-12.

Baez S, Ibanez A, Gleichgerrcht E, Perez A, Roca M, Manes F, et al. The utility of IFS (INECO Frontal Screening) for the detection of executive dysfunction in adults with bipolar disorder and ADHD. Psychiatry Res. 2014;216:269-76.

Barkley RA. Behavioral inhibition, sustained attention, and executive functions: Constructing a unifying theory of ADHD. Psychol Bull. 1997;121:65-94.

Barkley RA, Fischer M, Smallish L, Fletcher K. The persistence of attention-deficit/hyperactivity disorder into young adulthood as a function of reporting source and definition of disorder. J Abnorm Psychol. 2002;111:279-89.

Berman AH, Bergman H, Palmstierna T, Schlyter F. Evaluation of the Drug Use Disorders Identification Test (DUDIT) in criminal justice and detoxification settings and in a Swedish population sample. Eur Addict Res. 2005;11:22-31.

Bora E. Neurocognitive features in clinical subgroups of bipolar disorder: A meta-analysis. J Affect Disord. 2018;229:125-34.

Bora E, Hıdıroğlu C, Özerdem A, Kaçar ÖF, Sarısoy G, Civil Arslan F, et al. Executive dysfunction and cognitive subgroups in a large sample of euthymic patients with bipolar disorder. Eur Neuropsychopharmacol. 2016;26:1338-477.

Bourne C, Aydemir O, Balanzá-Martínez V, Bora E, Brissos S, Cavanagh JTO, et al. Neuropsychological testing of cognitive impairment in euthymic bipolar disorder: An individual patient data meta-analysis. Acta Psychiatr Scand 2013;128:149-62.

Brown TE. ADD/ADHD and impaired executive function in clinical practice. Curr Psychiatry Rep. 2008;10:407-11

Brus MJ, Solanto MV, Goldberg JF. Adult ADHD vs. bipolar disorder in the DSM-5 era: a challenging differentiation for clinicians. J Psychiatr Pract. 2014;20:428-37.

Burdick KE, Russo M, Frangou S, Mahon K, Braga RJ, Shanahan M, et al. Empirical evidence for discrete neurocognitive subgroups in bipolar disorder: Clinical implications. Psychol Med. 2014;44:3083-96.

Davidson MA. ADHD in adults: A review of the literature. J Atten Disord. 2008:11:628-41.

Depp CA, Mausbach BT, Harmell AL, Savla GN, Bowie CR, Harvey PD, et al. Meta-analysis of the association between cognitive abilities and everyday functioning in bipolar disorder. Bipolar Disord. 2012;14:217-26.

Harmanci H, Çam Çelikel F, Etikan İ. Comorbidity of adult attention deficit and hyperactivity disorder in bipolar and unipolar patients. Noropsikiyatri Arsivi. 2016;53:257-62.

Hervey AS, Epstein JN, Curry JF. Neuropsychology of adults with attentiondeficit/hyperactivity disorder: A meta-analytic review. Neuropsychology. 2004;18:485-503.

Karaahmet E, Konuk N, Dalkilic A, Saracli O, Atasoy N, Kurçer MA, et al. The comorbidity of adult attention-deficit/hyperactivity disorder in bipolar disorder patients. Compr Psychiatry. 2013;54:549-55.

Kessler RC, Adler L, Ames M, Demler O, Faraone S, Hiripi E, et al. The World Health Organization adult ADHD self-report scale (ASRS): A short screening scale for use in the general population. Psychol Med. 2005;35:245-56.

Lezak MD, Howieson DB, Bigler ED, Tranel D. Neuropsychological Assessment. 5th ed. New York: Oxford University Press Inc.; 2012.

Mannuzza S, Klein RG, Klein DF, Bessler A, Shrout P. Accuracy of adult recall of childhood attention deficit hyperactivity disorder. Am J Psychiatry. 2002;159:1882-8.

Mann-Wrobel MC, Carreno JT, Dickinson D. Meta-analysis of neuropsychological functioning in euthymic bipolar disorder: An update and investigation of moderator variables. Bipolar Disord. 2011;13:334-42.

Mårland C, Lichtenstein P, Degl'Innocenti A, Larson T, Råstam M, Anckarsäter H, et al. The Autism-Tics, ADHD and other Comorbidities inventory (A-TAC): Previous and predictive validity. BMC Psychiatry. 2017;17:403.

Matt Alderson R, Kasper $\sqcup$, Hudec KL, Patros CHG. Attention-deficit/hyperactivity disorder (ADHD) and working memory in adults: a meta-analytic review. Neuropsychology. 2013;27:287-302.

Milberger S, Biederman J, Faraone SV, Murphy J, Tsuang MT. Attention deficit hyperactivity disorder and comorbid disorders: issues of overlapping symptoms. Am J Psychiatry. 1995;152:1793-9.

Nierenberg AA, Miyahara S, Spencer T, Wisniewski SR, Otto MW, Simon N, et al. Clinical and diagnostic implications of lifetime attention-deficit/ hyperactivity disorder comorbidity in adults with bipolar disorder: data from the first 1000 STEP-BD participants. Biol Psychiat. 2005;57:1467-73.

Pålsson E, Figueras C, Johansson AG, Ekman CJ, Hultman B, Östlind J, et al. Neurocognitive function in bipolar disorder: a comparison between bipolar I and II disorder and matched controls. BMC Psychiatry. 2013;13:165.

Perroud N, Cordera P, Zimmermann J, Michalopoulos G, Bancila V, Prada P, et al. Comorbidity between attention deficit hyperactivity disorder (ADHD) and bipolar disorder in a specialized mood disorders outpatient clinic. J Affect Disord. 2014;168:161-6.

Rapport MD, Chung KM, Shore G, Isaacs P. A conceptual model of child psychopathology: implications for understanding attention deficit hyperactivity disorder and treatment efficacy. J Clin Child Adolesc Psychol. 2001;30:48-58

Robinson LJ, Ferrier IN. Evolution of cognitive impairment in bipolar disorder: a systematic review of cross-sectional evidence. Bipolar Disord. 2006:8:103-16.

Rolstad S, Jakobsson J, Sellgren C, Ekman CJ, Blennow K, Zetterberg H, et al. Cognitive performance and cerebrospinal fluid biomarkers of neurodegeneration: a study of patients with bipolar disorder and healthy controls. PLOS ONE. 2015;10:e0127100.

Rucklidge JJ. Impact of ADHD on the neurocognitive functioning of adolescents with bipolar disorder. Biol Psychiat. 2006;60:921-8.

Rydén E, Thase ME, Stråht D, Åberg-Wistedt A, Bejerot S, Landén M. A history of childhood attention-deficit hyperactivity disorder (ADHD) impacts 
clinical outcome in adult bipolar patients regardless of current ADHD. Acta Psychiatr Scand. 2009;120:239-46.

Sachs GS, Thase ME, Otto MW, Bauer M, Miklowitz D, Wisniewski SR, et al. Rationale, design, and methods of the systematic treatment enhancement program for bipolar disorder (STEP-BD). Biol Psychiat. 2003;53:1028-42.

Saunders JB, Aasland OG, Babor TF, De La Fuente JR, Grant M. Development of the alcohol use disorders identification test (AUDIT): WHO collaborative project on early detection of persons with harmful alcohol vonsumptionII. Addiction. 1993;88:791-804.

Savitz J, Van Der Merwe L, Stein DJ, Solms M, Ramesar R. Neuropsychological status of bipolar I disorder: Impact of psychosis. Br J Psychiatry. 2009:194:243-51.

Schoechlin C, Engel RR. Neuropsychological performance in adult attentiondeficit hyperactivity disorder: meta-analysis of empirical data. Arch Clin Neuropsychol. 2005;20:727-44.

Sheehan DV, Lecrubier Y, Sheehan KH, Amorim P, Janavs J, Weiller E, et al. The The mini-international neuropsychiatric interview (M.I.N.I.): the development and validation of a structured diagnostic psychiatric interview for DSM-IV and ICD-10. J Clin Psychiatry. 1998;59:22-33.

Silva KL, Rovaris DL, Guimarães-da-Silva PO, Victor MM, Salgado CA, Vitola ES, et al. Could comorbid bipolar disorder account for a significant share of executive function deficits in adults with attention-deficit hyperactivity disorder? Bipolar Disord. 2014;16:270-6.

Sparding T, Silander K, Palsson E, Östlind J, Sellgren C, Ekman CJ, et al. Cognitive functioning in clinically stable patients with bipolar disorder I and II. PLOS ONE. 2015;10:e0115562.

Sparding T, Silander K, Pålsson E, Östlind J, Ekman CJ, Sellgren CM, et al. Classification of cognitive performance in bipolar disorder. Cognitive Neuropsychiatry. 2017;22:407-21.

Tamam L, Karakus G, Ozpoyraz N. Comorbidity of adult attention-deficit hyperactivity disorder and bipolar disorder: prevalence and clinical correlates. Eur Arch Psychiatry Clin Neurosci. 2008;258:385-93.
Torralva T, Gleichgerrcht E, Torrente F, Roca M, Strejilevich SA, Cetkovich M, et al. Neuropsychological functioning in adult bipolar disorder and ADHD patients: a comparative study. Psychiatry Res. 2011;186:261-6.

Torres IJ, Boudreau VG, Yatham LN. Neuropsychological functioning in euthymic bipolar disorder: a meta-analysis. Acta Psychiatr Scand Suppl. 2007;116:17-26.

Torres I, Gómez N, Colom F, Jiménez E, Bosch R, Bonnín CM, et al. Bipolar disorder with comorbid attention-deficit and hyperactivity disorder main clinical features and clues for an accurate diagnosis. Acta Psychiatr Scand. 2015;132:389-99.

Torres I, Sole B, Corrales M, Jiménez E, Rotger S, Serra-Pla JF, et al. Are patients with bipolar disorder and comorbid attention-deficit hyperactivity disorder more neurocognitively impaired? Bipolar Disord. 2017;19:637-50.

Ward MF, Wender PH, Reimherr FW. The Wender Utah rating scale: an aid in the retrospective diagnosis of childhood attention deficit hyperactivity disorder. Am J Psychiatry. 1993;150:885-90.

Wingo AP, Ghaemi SN. A systematic review of rates and diagnostic validity of comorbid adult attention-deficit/hyperactivity disorder and bipolar disorder. J Clin Psychiatry. 2007;68:1776-844.

Yatham LN, Torres IJ, Malhi GS, Frangou S, Glahn DC, Bearden CE, et al. The international society for bipolar disorders-battery for assessment of neurocognition (ISBD-BANC). Bipolar Disord. 2010;12:351-63.

Young RC, Biggs JT, Ziegler VE, Meyer DA. A rating scale for mania: reliability, validity and sensitivity. Br J Psychiatry. 1978;133:429-35.

\section{Publisher's Note}

Springer Nature remains neutral with regard to jurisdictional claims in published maps and institutional affiliations.

\section{Submit your manuscript to a SpringerOpen ${ }^{\odot}$ journal and benefit from:}

- Convenient online submission

- Rigorous peer review

- Open access: articles freely available online

- High visibility within the field

- Retaining the copyright to your article

Submit your next manuscript at $\boldsymbol{\nabla}$ springeropen.com 